\title{
A Novel Photodiode for Reflectance Pulse Oximetry in low-power applications
}

Haahr, Rasmus Grønbek; Duun, Sune; Birkelund, Karen; Raahauge, P.; Petersen, P.; Dam, Henrik Friis; Nørgaard, Lars; Thomsen, Erik Vilain

\section{Published in:}

Proceedings of 29th IEEE Engineering in Medicine and Biology Conference

Link to article, DOI:

10.1109/IEMBS.2007.4352798

Publication date:

2007

Document Version

Publisher's PDF, also known as Version of record

Link back to DTU Orbit

Citation (APA):

Haahr, R. G., Duun, S., Birkelund, K., Raahauge, P., Petersen, P., Dam, H. F., Nørgaard, L., \& Thomsen, E. V. (2007). A Novel Photodiode for Reflectance Pulse Oximetry in low-power applications. In Proceedings of 29th IEEE Engineering in Medicine and Biology Conference (pp. 2350-2353). IEEE. https://doi.org/10.1109/IEMBS.2007.4352798

\section{General rights}

Copyright and moral rights for the publications made accessible in the public portal are retained by the authors and/or other copyright owners and it is a condition of accessing publications that users recognise and abide by the legal requirements associated with these rights.

- Users may download and print one copy of any publication from the public portal for the purpose of private study or research.

- You may not further distribute the material or use it for any profit-making activity or commercial gain

- You may freely distribute the URL identifying the publication in the public portal 


\title{
A Novel Photodiode for Reflectance Pulse Oximetry in low-power applications
}

\author{
Rasmus G. Haahr, Sune Duun, Karen Birkelund, Palle Raahauge, Peter Petersen, \\ Henrik Dam, Lars Nørgaard, and Erik V. Thomsen
}

\begin{abstract}
The amount of light collected is crucial for lowpower applications of pulse oximetry. In this work a novel ring-shaped backside photodiode has been developed for a wearable reflectance pulse oximeter. The photodiode is proven to work with a dual LED with wavelengths of $660 \mathrm{~nm}$ and $940 \mathrm{~nm}$. For the purpose of continuously monitoring vital signs of a human, a temperature sensor is integrated onto the chip containing the photodiode. This biomedical multisensor chip is made for integration into "the Electronic Patch", an autonomous monitoring system for humans.
\end{abstract}

\section{INTRODUCTION}

Microsystems utilized in medico technology have a perspective of attaching small measuring or dosing systems on humans. Theses devices are small compared to conventional medical equipment which force patients to stay at hospitals and often also to lie in bed such that instruments can be attached. This is both inconvenient for the patients and expensive for the health care system. Small integrated systems allow patients to keep their mobility and open up for home care nursing using telemedicine solutions.

Pulse oximetry is an intensively used non-invasive method for measuring the arterial oxygen saturation $\left(\mathrm{SpO}_{2}\right)$ with the purpose of detecting hypoxemia which can result in brain damage or death.

We have previously described a new patient monitoring system - the Electronic Patch (EP) [1], which is an in vivo platform for continuously monitoring body parameters, Fig. 1. The system is attached to the body with a sticking patch containing sensors, an ASIC solution for signal processing, and wireless communication based on a SWM1601 radio chip. The electronic patch is powered by a CR-2025 coin battery and is intended for use on heart disease patients hospitalized in their own home and for professionals in high risk working environments.

In this work we have developed a pulse oximetry sensor for the electronic patch. Since the patch is planar, reflection mode pulse oximetry is employed. The problem of artifacts in the signal due to motion is often mentioned in the literature [2]. In the EP the photodiode and light source are fixed to the body by a sticking patch which minimizes the motion artifacts due to the movement of the photo detector and light source relative to each other.

This work was supported by the Danish Ministry of Science, Technology and Innovation.

The authors are all with the Department of Micro and Nanotechnology, Technical University of Demark, 2800 Kgs. Lyngby, Denmark. rasmus.haahramic.dtu.dk

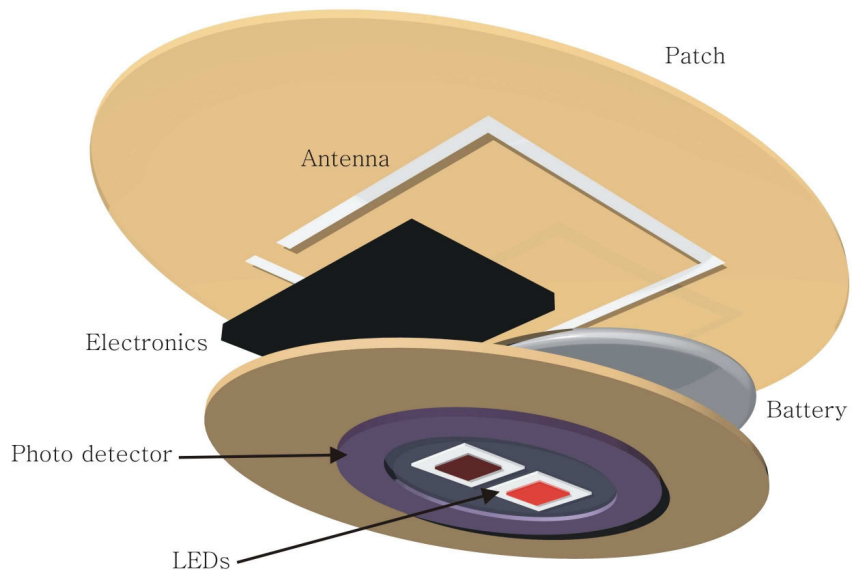

Fig. 1. Illustration of the developed electronic patch. The patch has a size of $20 \mathrm{~cm}^{2}$ and is $5 \mathrm{~mm}$ thick.

In the literature reflection mode pulse oximetry sensors have previously been reported: Studies have been conducted using one photo detector and one light source by Mendelson et al. [3] and Dassel et al. [4]. An early design using multiple photo detectors with a single light source was made by Mendelson et al. [5] and more recently power optimization has been studied [6]. Other design approaches have also been studied: Takatani et al. have studied a design using 20 LEDs placed concentrically around a single photo detector [7], [8]; however, these designs were used to study the quality of the signal and not low power applications which is the case with the EP. A finger-ring type of pulse oximeter intended for ambulatory use has been developed and studied by both Asada et al. [9], [10] and Mendelson et al. [11].

A physiologically monitoring system worn on the wrist for measuring several body parameters including $\mathrm{SpO}_{2}$ has been reported by Yoo [12]. This system uses a conventional finger probe attached on the finger which is connected by a wire to the monitoring unit on the wrist.

We report a pulse oximeter based on a ring-shaped photodiode with a hole in the middle for the light source as shown in Fig. 1. The photodiode collects backscattered light from the tissue all the way around the light source, therefore as much as possible of the backscattered light will be collected by the photodiode. This allows for a very low LED drive current which will lower the power consumption by the device. Furthermore, we have integrated an anti-reflection optical filter on the photodiode for enhanced sensitivity. In 


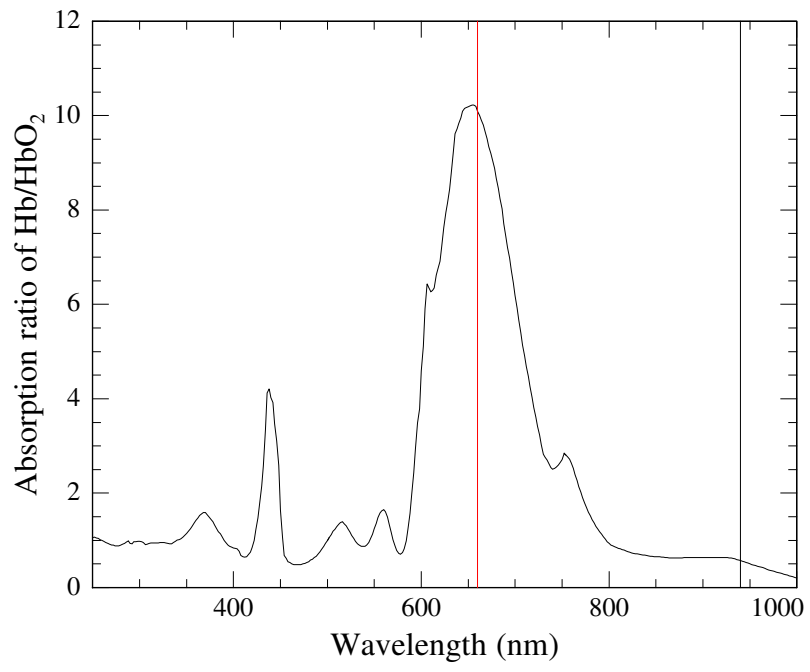

Fig. 2. Ratio between the absorption coefficients of de-oxygenated and oxygenated hemoglobin. The plot is based on data from [13].

addition to the photodiode the chip also contains a thermistor for measuring the body surface temperature, thereby creating a multisensor for medical purposes on a single chip.

\section{A. Pulse Oximetry}

Pulse oximetry is a spectrophotometric method for noninvasive measurement of the arterial oxygen saturation and can generally be performed in either transmission or reflection modes. In the first, light is transmitted through the tissue e.g. a finger and in the latter light is backscattered from the tissue. The method relies on a difference in the absorption spectra of oxygenated and de-oxygenated hemoglobin. The ratio between these is seen in Fig. 2. It is seen that the ratio has a peak at approximately $660 \mathrm{~nm}$ and at higher wavelengths the ratio is lower than one. Two wavelengths must be used since we have two absorption spectra. Conventionally, $660 \mathrm{~nm}$ (red) and $940 \mathrm{~nm}$ (IR) are used since the absorption ratio is large and small at those wavelengths respectively. This minimizes the uncertainty of the $\mathrm{SpO}_{2}$ measurement. By rapidly blinking (a frequency much higher than the heart beat rate) with the red and IR light sources two photoplethysmograms (optical recordings of the cardiovascular cycle), one for each wavelength, are recorded. The $\mathrm{SpO}_{2}$ is a function of the measured magnitude at the systolic and diastolic states of the two photoplethysmograms:

$$
\mathrm{SpO}_{2} \sim \ln \left(\frac{\operatorname{red}_{\text {systole }}}{\text { red }_{\text {diastole }}}\right) / \ln \left(\frac{\mathrm{IR}_{\text {systole }}}{\mathrm{IR}_{\text {diastole }}}\right)
$$

where red $_{\text {systole }}$ and red $_{\text {diastole }}$ are the magnitudes of the red light measured at the systolic state and diastolic state respectively and likewise for $\mathrm{IR}_{\text {systole }}$ and $\mathrm{IR}_{\text {diastole. How- }}$ ever, measurement of $\mathrm{SpO}_{2}$ normally relies on empirical calibration [2].

\section{DESIGN OF CHIP AND PHOTODIODE}

The multisensor chip with the photodiode and thermistor developed in this work has several novel features. The front-

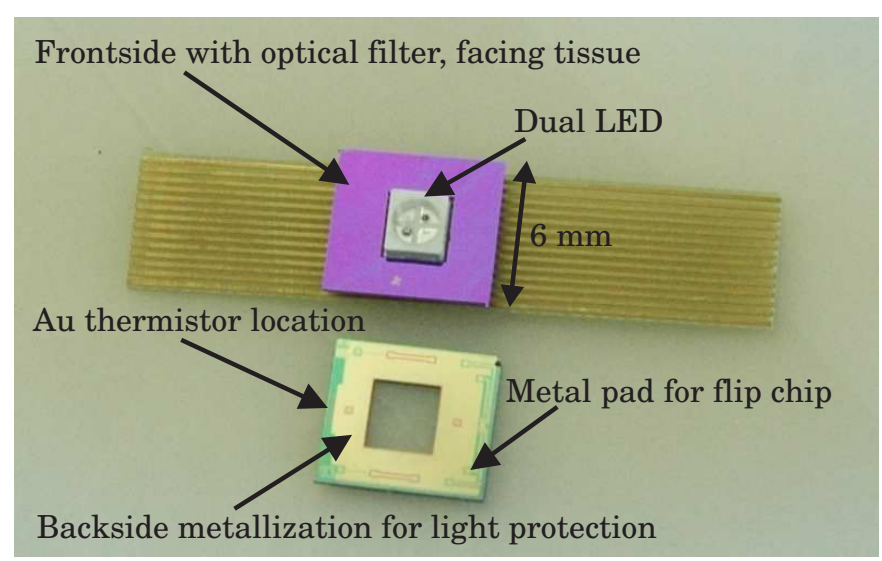

Fig. 3. Picture of the chip with the ring-shaped photodiode and the $\mathrm{Au}$ thermistor. The diode junction is made on the opposite site of the light entrance to avoid metallization and wiring to the frontside facing the tissue.

and backside of the chip together with a Ledtronics dual LED with wavelengths of $660 \mathrm{~nm}$ and $940 \mathrm{~nm}$ is seen in Fig. 3. The chip has a hole in the middle of $3.3 \times 3.6 \mathrm{~mm}^{2}$ which fits to the dual LED. The photodiode is defined as a single ring-shaped structure concentrically around the hole with an inner radius of $3.29 \mathrm{~mm}$ and an outer radius of 4.07 $\mathrm{mm}$ yielding an active area of $18 \mathrm{~mm}^{2}$. The actual diode junction is made on the opposite side of the light entrance to avoid metallization and wiring to the surface facing the skin. This therefore creates a backside photodiode where photons are absorbed by generation of minority carriers in the base substrate and these then diffuse to the diode junction. The diode is fabricated in p-type silicon since minority electrons have approximately a factor of 2 higher diffusivity compared to holes.

The front side of the chip has an anti-reflection filter which allows transmission of $98 \%$ for wavelengths of $660 \mathrm{~nm}$ and $940 \mathrm{~nm}$ which enhance the sensitivity of the device, Fig. 4. The filter is developed so that other wavelengths are suppressed to screen off stray light. The peak at $515 \mathrm{~nm}$ is less important due to a shorter photon penetration depth in the base material and a high absorbance by tissue at shorter wavelengths [13]. The filter is made by a stack of $50 \mathrm{~nm}$ silicon oxide and $550 \mathrm{~nm}$ silicon nitride.

An Au metal thermistor, made in a meander structure with a total length of $17.8 \mathrm{~cm}$, a width of $3 \mu \mathrm{m}$ and a height of $200 \mathrm{~nm}$, is integrated on the chip for measurement of body temperature on the skin surface.

\section{RESULTS}

\section{A. Diode characteristics}

A current-voltage characteristic for the photodiode is shown in Fig. 5. The photodiode has a forward saturation current density of $\mathrm{J}_{\mathrm{s}}=167 \mathrm{pA} / \mathrm{cm}^{2}$ and an ideality factor of $n=1.19$ showing that the diode is close to ideal. Some generation current is observed as seen from the deviation from the fit in the range 0 to $0.12 \mathrm{~V}$. The series resistance of the mounted chip on a printed circuit board is $R_{s}=84$ $\Omega$. We have obtained a quantum efficiency of 0.65 and 0.7 


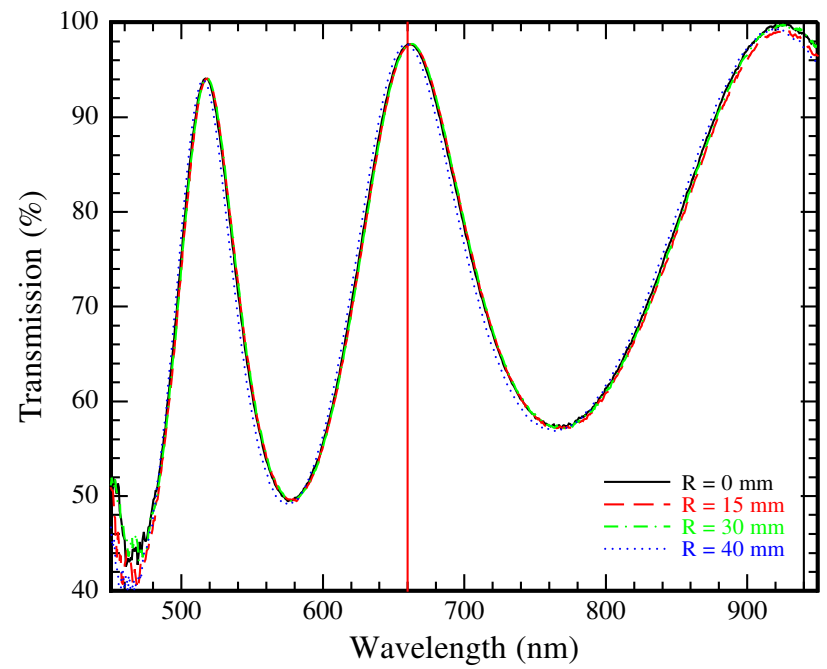

Fig. 4. Transmission of the $\mathrm{SiO}_{2}$ and $\mathrm{SiN}$ interference filter measured with a Filmtek reflectometer. The transmission uniformity across a wafer is seen to be good since there is no significant deviation in transmission between the four plots measured at a radius, $\mathrm{R}$, from the wafer center.

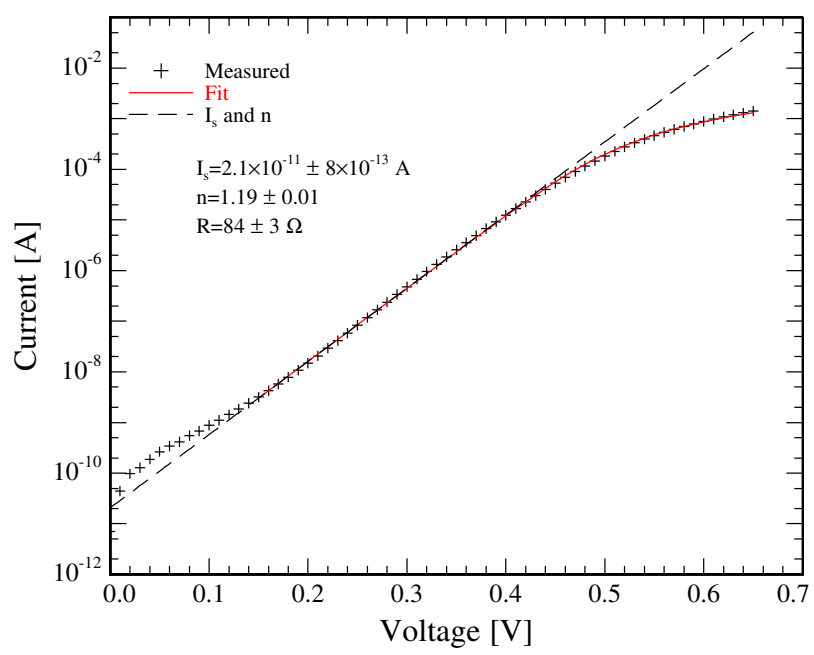

Fig. 5. Current-voltage characteristic of the fabricated photodiode. The photodiode ring has inner radius $3.29 \mathrm{~mm}$ and outer radius $4.07 \mathrm{~mm}$ yielding an active area of $18 \mathrm{~mm}^{2}$.

at wavelengths of $660 \mathrm{~nm}$ and 940 . This is reasonable for the current design of the photodiode, but less than that of high-end commercial photodiodes and solar cells.

\section{B. Au thermistor characteristics}

A measurement of resistance as a function of temperature is shown in Fig. 6. The thermistor is found to have a resistance of $13.6 \mathrm{k} \Omega$ at $37^{\circ} \mathrm{C}$ and a temperature of resistance ratio (TCR) of $2.6 \cdot 10^{-3} \mathrm{~K}^{-1}$. This is a little less than that of pure $\mathrm{Au}\left(3.4 \cdot 10^{-3} \mathrm{~K}^{-1}\right)$ and it is believed to be due to a non lattice structure of the deposited Au compared to bulk Au.

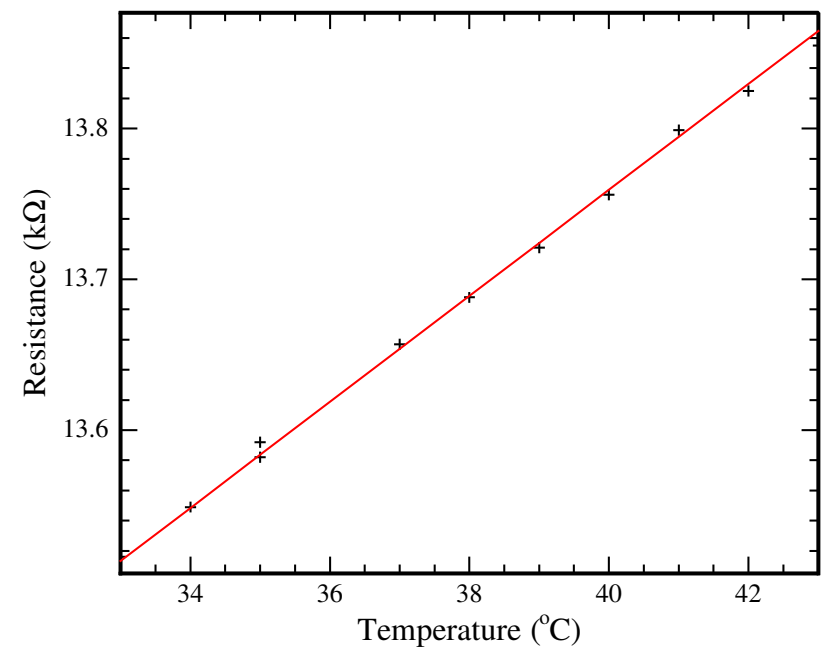

Fig. 6. Resistance dependance of temperature for the Au thermistor.

\section{Photoplethysmograms}

The fabricated photodiode packaged with a dual LED, as shown in Fig. 3, has been tested as a pulse oximeter on a test person's pulp of the left hand index finger. The result is shown in Fig. 7. The two recorded photoplethysmograms for the red and IR light both clearly display the cardiovascular cycle. The data are obtained by blinking with the red and IR LED elements with a frequency of $4 \mathrm{kHz}$ and $180^{\circ}$ out of phase. Data are sampled with $8 \mathrm{kHz}$. The data collection is done using Labview and the data have been processed with a moving average using a rectangular window with a width of 401 data points. The photoplethysmograms are also corrected for drift. The photoplethysmograms using red and IR light are plotted against the left and right abscissas respectively. From (1) a ratio of 0.7 is obtained. In [2] a simple theoretical model for the calibration is derived. Using this it is found that the ratio in (1) of 0.7 corresponds to a $\mathrm{SpO}_{2}$ of approximately $85 \%$. Even though the pulse oximeter has not been empirically calibrated in a clinical setup the result indicates that it works properly.

\section{FABRICATION}

The process fabrication sequence is shown in Fig. 8. The starting point is a $300 \mu \mathrm{m}$ thick 4 " p-type silicon floatzone wafer with a boron doping of $5 \cdot 10^{15} \mathrm{~cm}^{-3}$ and $1 \mathrm{~ms}$ minority carrier lifetime. A $765 \mathrm{~nm}$ thermal wet silicon oxide is grown. Alignment marks and the opening of the $\mathrm{SiO}_{2}$ at the photodiode area are done by photolithography and etching in buffered hydrofluoric acid (bHF) with the backside protected by a photoresist. A $1 \mathrm{~h}$ phosphor pre-deposition is done at $1000^{\circ} \mathrm{C}$. Another wet oxidation for $1 \mathrm{~h}$ at $1000^{\circ} \mathrm{C}$ is performed to make alignment marks and a masking silicon oxide for boron pre-deposition at the contacting areas. The masking silicon oxide are opened with bHF using photolithography. The boron pre-deposition is performed for $1 \mathrm{~h}$ at $975^{\circ} \mathrm{C}$ giving a $1 \mu \mathrm{m}$ deep doping profile, Fig. 8(a). The masking silicon oxide is removed in bHF and a $50 \mathrm{~nm}$ dry silicon 


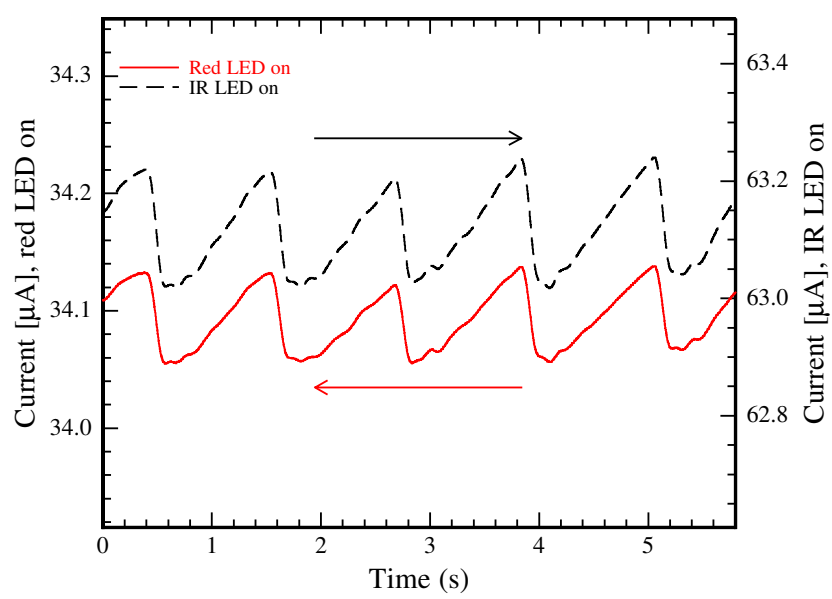

Fig. 7. Photoplethysmograms measured with the developed ring-shaped photodiode.

oxide is grown on both sides of the wafer. On the skin side it serves as the first layer for the optical filter and to give a low surface recombination velocity. On the side of the diode junction it serves as electrical isolation. Hereafter, a $550 \mathrm{~nm}$ PECVD silicon nitride is deposited for the second filter layer and electric passivation, Fig. 8(b). Contact holes are defined using photolithography and opened with bHF. Contacts, Au thermistor, and metallization for reflection of light from the top side of the wafer are made by evaporation of $20 \mathrm{~nm} \mathrm{Cr}$ and $200 \mathrm{~nm} \mathrm{Au}$ using an Alcatel e-beam evaporator, Fig. 8(c). The chromium is used to give a good adhesion to the silicon nitride. In the last step the hole for the dual LED is defined using backside photolithography and a hole is etched through the wafer from the skin side (lower side on Fig. 8(d)) with a STS Advanced Silicon Etcher, ASE.

\section{CONCLUSION AND FUTURE WORKS}

\section{A. Conclusions}

A multisensor chip for measurements of temperature and pulse oximetry $\left(\mathrm{SpO}_{2}\right)$ is reported. The chip has a novel ringshaped backside photodiode with a special designed optical filter for pulse oximetry in low-power applications, and an $\mathrm{Au}$ thermistor. The design and fabrication of the photodiode and the thermistor has been presented. The photodiode and the thermistor has been characterized and proven to work as a pulse oximeter; however, more advanced photodiode designs could be considered to further enhance the quantum efficiency. The chip has been packaged together with a dual LED of $660 \mathrm{~nm}$ and $940 \mathrm{~nm}$ into a compact pulse oximeter which is compatible with integration into the Electronic Patch, Fig. 1.

\section{B. Future Works}

The pulse oximeter should be completely integrated into the Electronic Patch for optimizing the systems with respect to measuring sites on the body and power consumption. The monitoring systems should then be evaluated in clinical trials.

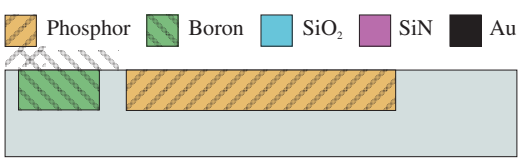

(a) First phosphor doping then boron doping.

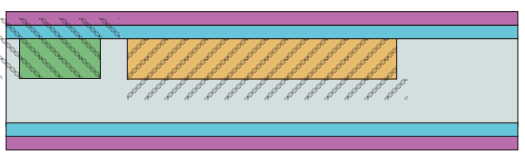

(b) $\mathrm{SiO}_{2}$ and $\mathrm{SiN}$ deposition for optical filter.

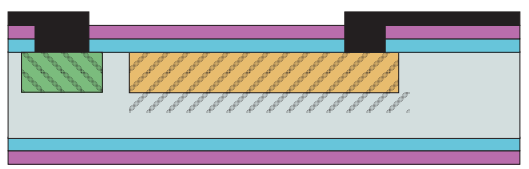

(c) Contact and thermistor metallization.

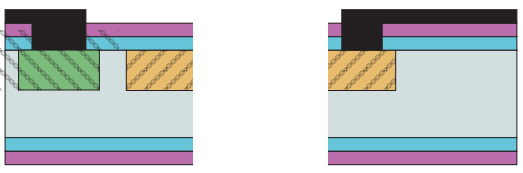

(d) ASE etch of hole for LED's.

Fig. 8. Process sequence for the ring shaped photodiode for pulseoximetry.

\section{ACKNOWLEDGMENTS}

The authors gratefully acknowledge the The Danish Ministry of Science, Technology and Innovation for financing.

\section{REFERENCES}

[1] E. V. Thomsen, A. Hyldgård, K. Birkelund, R. G. Haahr, S. Duun, R. Elsubaihi, J. Branebjerg, "Distributed sensors: Applications, fabrication and challenges", Proc. Eurosensors XX, 2006

[2] J. G. Webster, Design of Pulse Oximeters, IOP Publishing, UK; 1997.

[3] Y. Mendelson, "Noninvasive pulse oximetry utilizing skin reflectance photoplethysmography", IEEE Transactions on Biomedical Engineering, vol. 35, nr. 10, pp 798-805, 1988

[4] A.C. Dassel, "Reflectance Pulse oximetry in fetal lambs", Pediatr. Res., vol. 31, nr. 6 pp 266-269, 1992

[5] Y. Mendelson, "Design and evaluation of a new reflectance pulse oximeter sensor", Medical Instrumentation, vol. 22, nr. 4, pp 167173,1988

[6] Y. Mendelson, "Measurement site and photodetector size considerations in optimizing power consuption of a wearable reflectance pulse oximeter", Proc. 25th Annual IEEE EMBS conf., pp 3016-3019, 2003

[7] S. Takatani, "A new hybrid reflectance optical pulse oximetry sensor for lower oxygen saturation measurements and for broader clinical applications", Proc. SPIE, nr. 2976, pp 78-87, 1997

[8] S. Takatani, "A novel hybrid reflectance pulse oximeter sensor with improved linearity and general applicability to various portions of the body", Proc. 20th Annual IEEE EMBS conf., vol. 20, nr. 4, pp 18581861,1998

[9] H. Asada, "The Ring Sensor: a New Ambulatory Wearable Sensor for Twenty-Four Hour Patient Monitoring", Proc. 20th Annual IEEE EMBS conf., vol. 4, pp 1906-1909, 1998

[10] H. Asada, "Artifact-resistant power-efficient design of finger-ring plethysmographic sensors", IEEE Transactions on Biomedical Engineering, vol. 48, nr. 7, pp 795-805, 2001

[11] Y. Mendelson, "Minimazation of LED power consumption in the design of a wearable pulse oximeter", Proc. IASTED Conf. on Biomedical Engineering, pp 249-254, 2003

[12] T. Yoo, "A wrist-worn integrated health monitoring instrument with a tele-reporting device for telemedicine and telecare", IEEE Transactions on Instrumentation and Measurement, vol. 55, nr. 5, pp 16551661,2006

[13] Scott Prahl, Oregon Medical Laser Center, http://omlc.ogi.edu, Portland, OR, 1998. 